\title{
HACIA UNA HISTORIA DE LA FIGURACIÓN MARGINAL
}

\author{
POR \\ FERNANDO GUTIÉRREZ BAÑOS \\ Universidad de Valladolid
}

\begin{abstract}
This paper tries to set off the main problems to be found in the research of images in the margins of illuminated gothic manuscripts: their history and their meaning. Concerning their history the author goes through an accurate analysis of its periods, establishing an evolution line from their bloom at the middle of the $13^{\text {th }}$ century (paying attention to the different factors that made it possible), crisis around 1400 and new developments during the $15^{\text {th }}$ century to their disappearance around 1500 . Regarding their meaning, the author compares the points of view of several scholars while discussing the significant or non-significant character of these illustrations.
\end{abstract}

La variedad de figuras de todo tipo que se encuentra dispersa por los márgenes de una gran cantidad de manuscritos iluminados durante los siglos XIII, XIV y XV, a la que me refiero con la expresión «figuración marginal», ha llamado desde hace tiempo la atención de los medievalistas. Sin embargo, a pesar de algunas importantes aportaciones, se está todavía muy lejos de conocer de manera detallada toda su problemática. Estas líneas no pretenden otra cosa que aproximar la complejidad que encierra este interesante capítulo de la Historia del Arte de la Edad Media ofreciendo una síntesis sobre las distintas cuestiones que plantea su estudio.

Ciertas observaciones realizadas por algunos de los pocos estudiosos que se han aventurado en tan difícil campo pueden resultar de gran valor como puntos de partida en esta labor de síntesis. Henry, por ejemplo, señala que la presencia de decoración marginal en un manuscrito no depende de su «fondo», esto es, de su contenido, sino de su «forma», es decir, de su calidad ${ }^{1}$. Lyna, por su parte, hace hincapié en la necesidad de distinguir en la decoración marginal entre el soporte, constituido generalmente por motivos vegetales cuya evolución tanto él como Henry delinean con gran precisión y capacidad de síntesis, y la variedad de motivos adventicios que se disponen sobre él ${ }^{2}$. Para éstos se emplea a menudo modernamente el término drôlerie, extravagancia, si bien parece que en el siglo XIV se les denominaba curiositates o babuini, término éste en relación con el simio, uno de los animales que con mayor frecuencia aparece en la figuración marginal. En Inglaterra está documentado en el siglo XIV el empleo del término babewyn para la descripción en pinturas murales y en ob-

1 Henry, Suzanne: «La décoration marginale française dans les manuscrits du milieu du XIII ${ }^{\mathrm{e}}$ à la fin du $\mathrm{XV}^{\mathrm{c}}$ siècle», École Nationale des Chartes. Position des thèses, París, 1951, p. 79.

2 Lyna, Frédéric: «La bordure marginale dans les manuscrits flamands à l'époque gothique», Les BeauxArts, núm. especial, París, 1959, p. 1. 
jetos suntuarios de ciertos motivos análogos a los de la figuración marginal de los manuscritos contemporáneos y por esa misma época el jurista italiano Odofredo de Bolonia se quejaba de que, habiendo enviado a su hijo a París para que estudiase, en lugar de eso fecit libros suos babuinare. Al conjunto de la decoración marginal se le denominaba en la Edad Media vignette ${ }^{3}$.

Aunque se ha apuntado la existencia de precedentes en salterios bizantinos de la Alta Edad Media ${ }^{4}$ y aunque sin duda podrían rastrearse elementos precursores en manuscritos de las centurias que precedieron a su desarrollo a partir de mediados del siglo XIII, lo cierto es que la presencia de figuración marginal es un rasgo característico de buena parte de la miniatura gótica. En la eclosión de la figuración marginal confluyeron factores, señalados tanto por Randall como por Camille ${ }^{5}$, de muy diversa naturaleza, desde los puramente formales, de acuerdo con los cuales el surgimiento de la decoración marginal y de la figuración a ella ligada no sería sino el desarrollo lógico del estallido de las iniciales de los manuscritos de los siglos XII y XIII, cada vez más repletas de decoración, hasta los netamente sociales y culturales en relación con cambios como los nuevos modos de lectura ligados a la escolástica (en este sentido Camille insiste agudamente en la analogía entre glosa y figuración marginal) o como el incremento de la alfabetización y su extensión a nuevos grupos sociales, cambios que conllevaron un aprecio del libro por parte de sectores hasta entonces excluidos de su tráfico para los que sería tan estimable su dimensión visual como su dimensión textual (no en vano indica Randall que las zonas donde mayor desarrollo tuvo la figuración marginal a finales del siglo XIII y a comienzos del siglo XIV coinciden con las zonas europeas de más activo comercio), lo que incide en los cambios en la producción libraria y en su traslación del ámbito monástico al ámbito urbano, convertido ahora en mercado del arte y, desde este punto de vista, sujeto a los vaivenes de la moda, como otros de los factores que confluyeron en la eclosión de la figuración marginal, ya que a partir del siglo XIII la industria del libro se profesionalizó y se produjo en ella una división del trabajo que favoreció la especialización de funciones, entre ellas la del iluminador encargado de las figuras de los márgenes. En líneas generales se admite que la decoración marginal formaba parte del proceso integral de la producción de un manuscrito, aunque no faltan noticias, como la del díscolo hijo de Odofredo de Bolonia, que atestiguan una realización de la misma a posteriori. La laicización y la reordenación de la industria del libro a partir del siglo XIII invitan asimismo a pensar en la existencia de talleres perfectamente organizados en los que un maestro distribuiría el trabajo entre operarios especializados que, para el caso de la decoración marginal, se servirían de libros de modelos y de trucos para ahorrar tiempo como la repetición de una misma vignette, calcada al trasluz, en el recto y en el verso de un mismo folio ${ }^{6}$. La vernacularización de la religión, finalmente, y el creciente papel ju-

3 Lyna, Frédéric: «La bordure marginale...», 1. cit.; Baltrušaitis, Jurgis: Réveils et prodiges. Le gothique fantastique, París, 1960, pp. 197-199; Randall, Lilian M. C.: Images in the Margins of Gothic Manuscripts, University of California Press, Berkeley y Los Ángeles, 1966, p. 11; Camille, Michael: Image on the Edge. The Margins of Medieval Art, Reaktion Books, Londres, 1992, pp. 12-13 y 152.

4 Verdier, Philippe: «Woman in the Marginalia of Gothic Manuscripts and Related Works», en Morewedge, Rosmarie T. (ed.): The Role of Woman in the Middle Ages (Papers of the $6^{\text {th }}$ Annual Conference of the Center for Medieval and Early Renaissance Studies at the State University of New York, Binghamton, 1972), State University of New York Press, Albany, 1975, pp. 124-125.

5 Randall, Lilian M. C.: Images in the Margins..., pp. 8-9; Camille, Michael: Image on the Edge..., pp. 10, $18-24$ y $151-152$

${ }_{6}^{6}$ Henry, Suzanne: «La décoration...», p. 82. Meiss, por ejemplo, señala cómo, dejando a un lado raras excepciones, los hermanos Limbourg trabajaron siempre como pintores de miniaturas y cómo encargaron la 
gado en la misma por la predicación han sido señalados asimismo como factores que favorecieron el desarrollo de la figuración marginal ${ }^{7}$.

Espacio complejo y contradictorio, el margen ha sido caracterizado por igual como sede de las más sorprendentes fantasías y monstruosidades y como lugar del que surgieron los primeros acentos de acendrado realismo en el arte occidental, cuya repentina aparición en el arte flamenco del siglo XV respondería en realidad a una lejana tradición. Elementos de uno y de otro tipo convivieron sin límites aparentes, de tal suerte que en los márgenes de los manuscritos de los siglos XIII, XIV y XV se pueden encontrar tanto híbridos, animales fantásticos o seres monstruosos como espléndidos pájaros o imágenes de la vida cotidiana, amén de temas grotescos, a los que correspondió un especial protagonismo.

Aun cuando los factores que favorecieron el desarrollo de la figuración marginal han podido ser enumerados con una cierta precisión, todavía no está del todo claro dónde y cuándo surgió esta modalidad que se documenta desde mediados del siglo XIII en dos ámbitos tan distantes entre sí como lo son el entorno del canal de la Mancha y la ciudad italiana de Bolonia, sin que se deba olvidar la temprana y excepcional presencia de figuración marginal, estudiada por Domínguez Rodríguez, en la miniatura alfonsí, concretamente en el Lapidario (San Lorenzo de El Escorial, Real Biblioteca del Monasterio, ms. H.I.15) ${ }^{8}$. Esta diversidad geográfica remite a la complejidad de las corrientes artísticas del siglo XIII y a la problemática de las relaciones entre el mundo mediterráneo y el mundo nórdico, de la que la figuración marginal parece ser un interesante capítulo. Atendiendo únicamente al ámbito septentrional, Randall señala que la eclosión de la figuración marginal tuvo lugar en Inglaterra, si bien alcanzó de inmediato un gran desarrollo en el norte de Francia y en los Países Bajos, con tal grado de homogeneidad en lo que a sus temas y a sus características se refiere con respecto a la producción inglesa que se ha hablado de una única «Escuela del Canal» para englobar los manuscritos elaborados a uno y a otro lado del canal de la Mancha. Ya en el siglo XIV sus motivos fueron introducidos en la miniatura parisina de la mano de Jean $\mathrm{Pu}$ celle, pero pronto se observa en ella una escasez de nuevas ideas, en suma, una decadencia.

decoración marginal de sus manuscritos a colaboradores como el maestro del Breviario de Juan Sin Miedo (Meiss, Millard: French Painting in the Time of Jean de Berry: The Limbourgs and Their Contemporaries, Thames and Hudson, Londres, 1974, p. 184). En cambio, las averiguaciones de Calkins sobre la producción libraria en París a comienzos del siglo XV hablan a favor no tanto de grandes talleres organizados como de una red de miniaturistas individuales, aislados, a los que se asignarían trabajos en combinaciones variables bajo la supervisión de uno a quien se encargaría el control sobre el resultado final (Calkins, Robert G.: «An Italian in Paris: The Master of the Brussels Initials and His Participation in the French Book Industry», Gesta, volumen XX, Nueva York, 1981, p. 230). El procedimiento de calcar la vignette para ahorrar tiempo no es, como a veces se ha dicho, un recurso sugerido por las técnicas de producción propias de la imprenta, sino que está documentado con anterioridad, por ejemplo, en las denominadas Horas Guisa (Chantilly, Musée Condé, ms. 64), manuscrito rehecho en el siglo XVI que incluye folios cuya decoración marginal puede datarse a mediados de la segunda década del siglo XV en los que ya se aprecia este procedimiento (Meiss, Millard: French Painting in the Time of Jean de Berry: The Boucicaut Master, Phaidon Press y Phaidon Publishers, Londres y Nueva York, 1968, p. 81). En cuanto a la existencia de libros de modelos, se pone de manifiesto por la recurrencia de ciertas composiciones a lo largo no ya de un mismo manuscrito (Davenport, S. K.: «Illustrations Direct and Oblique in the Margins of an Alexander Romance at Oxford», Journal of the Warburg and Courtauld Institutes, volumen XXXIV, Londres, 1971, p. 91), sino de varios manuscritos (Randall, Lilian M. C.: Images in the Margins..., figs. 708-709, correspondientes a sendos manuscritos picardos de finales del siglo XIII).

7 Sobre estos dos últimos factores, véase, aparte de la bibliografía indicada en la nota anterior, Müller, Markus: «Fonctions du profane et du "ridiculum" dans l'enluminure médiévale», Histoire de l'Art, núms. 29-30, París, 1995, pp. 23-30.

8 Domínguez Rodríguez, Ana: Astrología y arte en el lapidario de Alfonso X el Sabio, Edilán, Madrid, 1982, pp. 61-64. 
A partir de mediados del siglo XIV la figuraciốn marginal entró en un período de zozobra del que tardará en salir ${ }^{9}$. El desarrollo de la misma en la miniatura boloñesa será fundamental para la recuperación de la drôlerie en la miniatura francesa a comienzos del siglo XV, en el contexto del estilo gótico internacional, en unos años en los que ya Inglaterra había perdido por completo cualquier capacidad rectora e innovadora en el campo de la iluminación de manuscritos. En efecto, los años en torno a 1400 fueron años de gran actividad y de flujo de ideas en lo que a los márgenes se refiere.

Por una parte, se asiste en ellos al definitivo periclitar de la tradición de la figuración marginal de los siglos XIII y XIV. Las Grandes Heures del duque de Berry (París, Bibliothèque nationale de France, ms. lat. 919), manuscrito completado en 1409, si bien un tanto alterado a finales del siglo $\mathrm{XV}$, representan este final. Sus espléndidos márgenes, aunque derivados en las páginas principales de los de las denominadas Horas de Bruselas, las Très Belles Heures del duque de Berry (Bruselas, Bibliothèque royale, mss. 11060-11061), incorporan en muchas de las páginas secundarias auténticas drôleries cuyos motivos son muy a menudo copias exactas de los motivos de Jean Pucelle (fig. 1), cuyo trabajo se había convertido en la referencia obligada para los pocos miniaturistas que a finales del siglo XIV se aventuraban en el terreno de la figuración marginal ${ }^{10}$. El malabarista que aparece en el margen derecho del folio 109r de las Grandes Heures (fig. 2) es copia del que aparece en el margen izquierdo del folio $6 \mathrm{v}$ del volumen primero del Breviario de Belleville (París, Bibliothèque nationale de France, ms. lat. 10483), folio en cuyo margen derecho se aprecia también la existencia de un híbrido femenino que toca una trompeta, presente también en el folio 150r de las Horas de Jeanne d'Évreux (Nueva York, The Metropolitan Museum of Art, The Cloisters Collection, Acc. 54 (1.2)), reproducido a su vez en el margen derecho del folio 18v de las Grandes Heures (fig. 3). Cabría insistir en este tejido de relaciones: el otro motivo que aparece en el margen derecho del folio 109r de las Grandes Heures retoma uno de los motivos del margen del folio $6 \mathrm{r}$ del volumen primero del Breviario de Belleville... Los miniaturistas que trabajaron para el duque de Berry en las Grandes Heures al menos tuvieron la habilidad de restituir a su sentido originario en cuanto que finales de línea los motivos de Pucelle, tal vez por haber podido examinar directamente el Breviario de Belleville, que llegó a las manos del duque de Berry no mucho después de 1399, si es que no dispusieron también de las Horas de Jeanne d'Évreux, cuya presencia en las colecciones del duque suscita alguna discusión. Sin embargo, su labor, excepcional en el conjunto de la obra producida para el duque de Berry, en la que, dejando a un lado el caso más problemático de las Très Riches Heures (Chantilly, Musée Condé, ms. 65) al que más adelante me referiré, tan sólo cabe señalar la existencia de algunas drôleries en las Petites Heures (París, Bibliothèque nationale de France, ms. lat. 18014), es el mejor testimonio del anquilosamiento de la vieja tradición y, en un panorama en el que la decoración marginal se encontraba dominada por exquisitos y livianos tallos repletos de hojas tripartitas que se enrollan sobre sí mismos, debió de resultar un tanto anacrónica.

9 Randall, Lilian M. C.: Images in the Margins..., pp. 9-10.

10 Meiss, Millard: French Painting in the Time of Jean de Berry: The Late Fourteenth Century and the Patronage of the Duke, Phaidon Press y Phaidon Publishers, Londres y Nueva York, 1967, pp. 257-259; Les Grandes Heures de Jean de France, duc de Berry, edición facsímil, introducción de Marcel Thomas, Draeger Frères, Éditeur, París, 1971, pp. xi-xiv. 

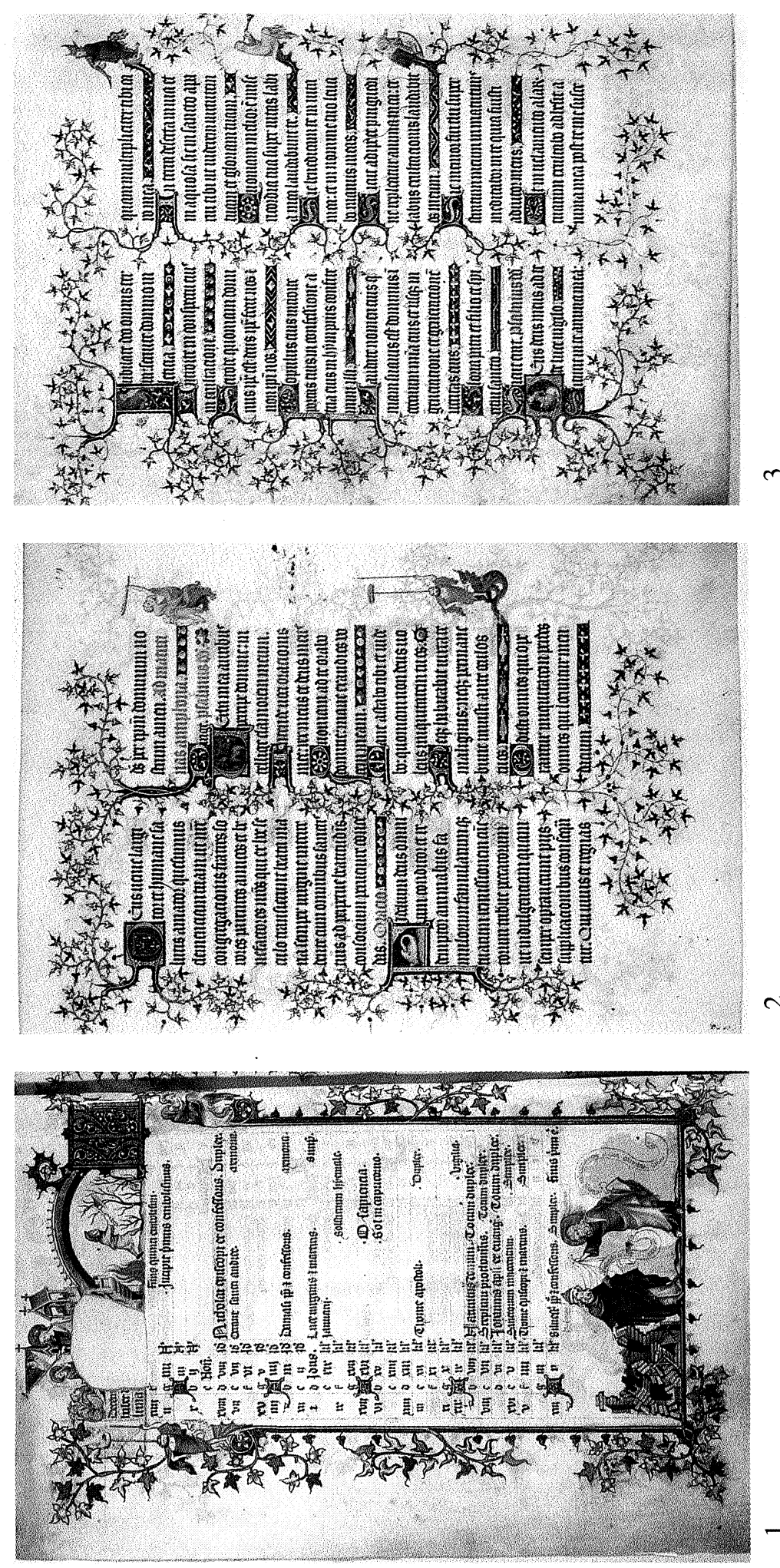

它

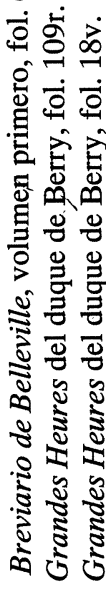

-i $\dot{r}$

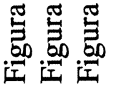


Por otra parte, en los años en torno a 1400 se asiste también al resurgir de la figuración marginal, resurgir que, claro está, no procede de la vía muerta de la vieja tradición, sino del aporte exterior, de la actividad en los talleres parisinos de un artista italiano excepcional, el maestro de las Iniciales de Bruselas ${ }^{11}$. Este miniaturista introdujo en los diversos manuscritos en los que trabajó durante su estancia parisina entre en torno a 1390-1395 y en torno a 1409 una decoración marginal típicamente italiana, dominada por grandes hojas de acanto multicolor en torno a las cuales y en los medallones por ellas conformados, tan caros a la tradición italiana, se disponen motivos figurativos frecuentemente grotescos, tal y como se aprecia, por ejemplo, en el folio 95r (fig. 4) de uno de los libros de horas en que intervino durante este período (Madrid, Real Biblioteca de Palacio, ms. II-2099), para el que Meiss propone una cronología en torno a 1400, mientras que Calkins prefiere situarlo en torno a 1407-1408. Aunque el acanto, empleado con anterioridad en la miniatura de Italia y de Bohemia, no era del todo desconocido en la miniatura francesa, parece ser que la actividad del maestro de las Iniciales de Bruselas fue decisiva para su adopción en la misma a lo largo de la primera década del siglo XV. Grandes maestros como los Limbourg o como el maestro de Boucicaut se sumaron muy pronto a la nueva moda, que supuso una transformación radical en la gama cromática de la decoración marginal y la restitución a la misma de los motivos figurativos abocados a su desaparición en la trayectoria de la miniatura francesa. Si bien en un primer momento estos motivos figurativos aparecieron casi siempre estrechamente ligados a la miniatura central del folio correspondiente, enseguida comenzaron a independizarse. Manuscritos reseñados por Meiss como las Horas Douce 144 (Oxford, Bodleian Library, ms. Douce 144) o como las Horas Corsini (Florencia, colección del príncipe Tommaso Corsini) ${ }^{12}$ atestiguan este proceso.

Final y principio, los años en torno a 1400 fueron también años en los que se plantearon las cuestiones que, a la postre, pondrían fin a la figuración marginal en poco menos de un siglo. Hasta ahora los manuscritos iluminados góticos se habían caracterizado por el mantenimiento de un equilibrio prácticamente perfecto entre texto, miniatura y decoración marginal, pero este equilibrio estaba llamado a romperse desde el momento y hora en que se cuestionase la planitud consustancial al espacio pictórico y se pretendiese la plasmación de un espacio tridimensional y coherente. Los pequeños medallones con escenas o motivos figurativos aislados que desde finales del siglo XIV comenzaron a aparecer de manera esporádica dispuestos regularmente por los márgenes supusieron ya una cierta ruptura de la continuidad y de la homogeneidad de la vignette al plantear ámbitos espaciales particulares que entraban en conflicto con la lógica de la decoración marginal, pero mucho más decisiva fue la búsqueda de ese espacio tridimensional y coherente en la propia miniatura que se produjo poco después con la adopción en la misma, desde comienzos del siglo XV, de un estilo decididamente pictórico, ya que ese cambio supuso la ruptura definitiva del viejo y tradicional equilibrio entre texto, miniatura y decoración marginal (en beneficio, claro está, de la segunda), con lo que a la decoración marginal, una vez negado el carácter específico de la labor de iluminación de manuscritos, tan sólo le quedaron las opciones de o bien convertirse en su marco o bien desaparecer. Ese fue, precisamente, el paso que dieron los Limbourg en las Très Riches Heures del duque de Berry

11 Meiss, Millard: French Painting... The Late Fourteenth Century..., p. 246; Calkins, Robert G.: «An Italian in Paris...», 1. cit.

12 Meiss, Millard: French Painting... The Boucicaut Master, pp. 86 y 106-107. 


y, por eso, tras varios tanteos, decidieron, según señala Meiss en contra de la opinión de Pächt, prescindir de la decoración marginal, dejando sus grandes miniaturas rodeadas de amplios márgenes en blanco (fig. 5) ${ }^{13}$. En algunas de las pocas páginas en las que se aventuraron con la decoración marginal, los Limbourg traicionaron su sentido originario, ya que ésta no es independiente, sino que busca la ficción de su adherencia al marco de la miniatura, entendido como el marco de un cuadro, tal y como ocurre en el caso de los magníficos caracoles del folio $168 \mathrm{v}$ (fig. 6), presidido por la miniatura en la que se representa el tema evangélico de la multiplicación de los panes y de los peces.

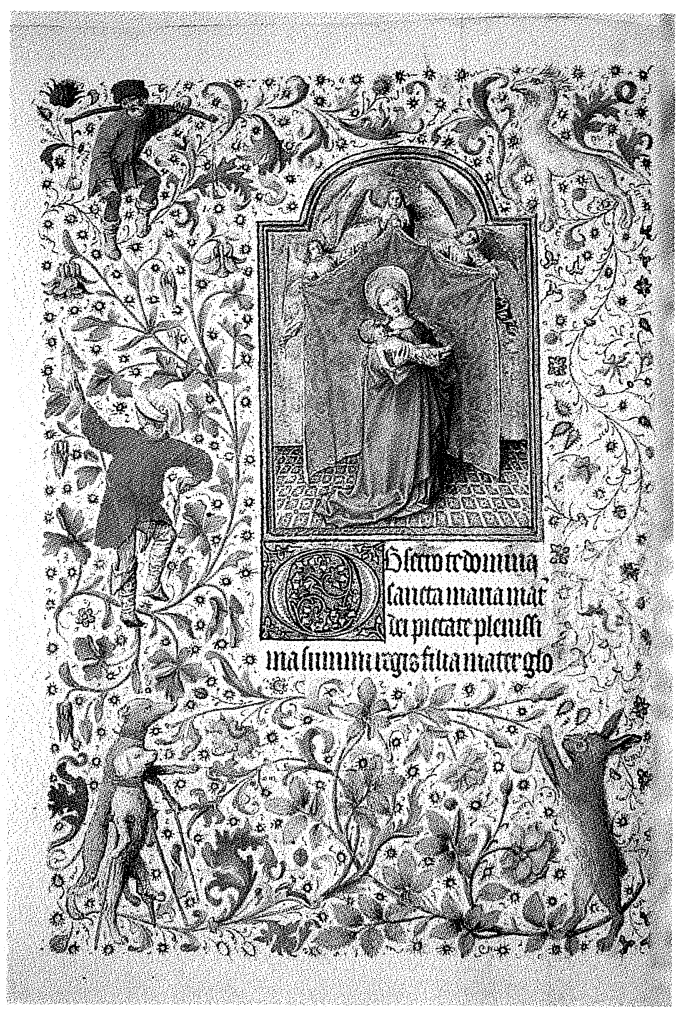

7

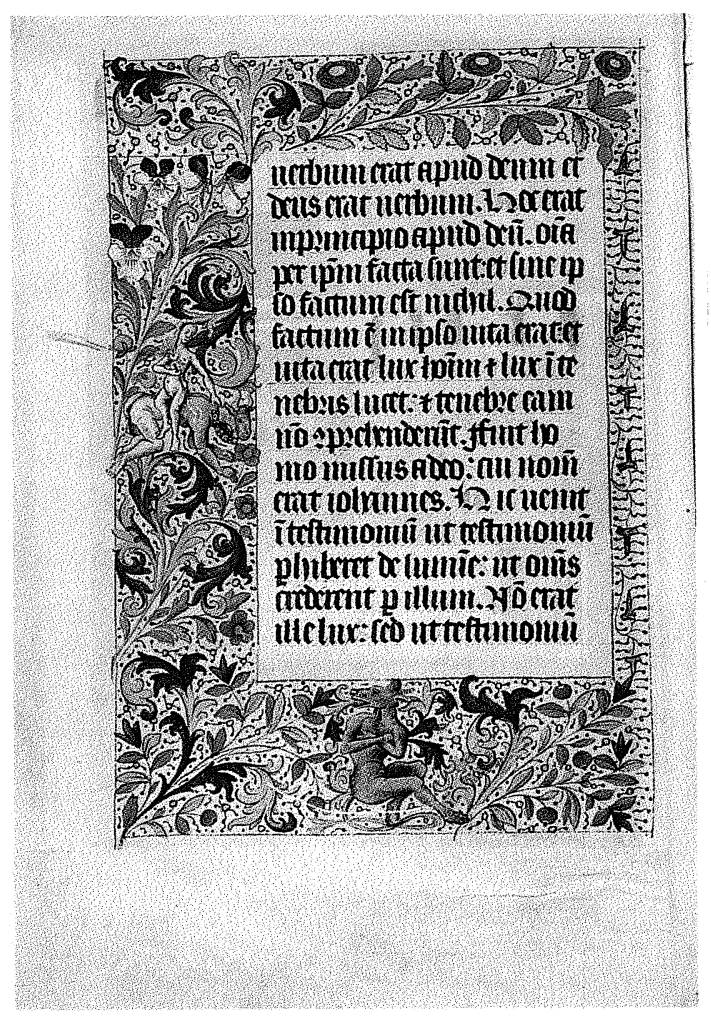

8

Figura 7. Horas Morgan, fol. 20v.

Figura 8. Libro de Horas; Madrid, Biblioteca Nacional, ms. Vit. 25-3, fol. 13v.

13 Meiss, Millard: French Painting... The Limbourgs..., pp. 179-181. Anteriormente Pächt había manifestado su opinión de que estos márgenes se dejaron en blanco porque el manuscrito habría quedado inconcluso (Pächt, Otto: The Master of Mary of Burgundy, Londres, 1948, p. 29). Véase además Klingender, Francis: Animals in Art and Thought to the End of the Middle Ages, Routledge \& Kegan Paul, Londres, 1971, pp. 476-479. 
La cuestión planteada por los Limbourg quedó por el momento en suspenso y la figuración marginal resucitada a comienzos del siglo XV invadió los márgenes de numerosos manuscritos franceses de las décadas siguientes. La producción libraria de estos años en las diversas escuelas refleja, en lo que a los márgenes se refiere, la ya larga historia de la miniatura francesa. Sobresale en este período por la riqueza de su figuración marginal el manuscrito de las denominadas Horas Morgan (Nueva York, The Pierpont Morgan Library, ms. 358), que habría sido iluminado por Barthélemy d'Eyck y por Enguerrand Quarton en torno a 1440-1450 (fig. 7) ${ }^{14}$, pero los ejemplos que cabría aducir son muy numerosos. Sirva, por su calidad, el de un libro de horas de en torno a 14501460 (Madrid, Biblioteca Nacional, ms. Vit. 25-3), obra de un seguidor del denominado maestro de Adelaida de Saboya o, más recientemente, maestro del ms. Poitiers 30 (fig. 8). Si Jean Fouquet se hubiera dedicado de una manera más plena a la miniatura tal vez hubiese podido aportar algún planteamiento nuevo a la cuestión en torno al destino de la decoración marginal que había quedado en suspenso a la muerte de los Limbourg, habida euenta de su formación, de su capacidad y de su estilo decididamente pictórico. Sin embargo, parece ser que el gran pintor de Tours nunca se ocupó de la producción libraria, limitándose tan sólo a la realización de magníficas miniaturas en aquellos manuscritos que le eran presentados ${ }^{15}$. De ahí la diversidad y la incoherencia, desde el punto de vista de la decoración marginal, de las distintas obras en las que intervino, de entre las que sobresalen por su figuración marginal (de factura no muy fina) los folios sueltos del Louvre de en torno a 1475 sobre temas de la Antigüedad (París, Musée du Louvre, Département des Arts Graphiques, R.F. 4143, R.F. 5271, R.F. 29493 y R.F. 29494). En cualquier caso, Francia no estaba llamada a protagonizar el siguiente episodio en la historia de la figuración marginal.

En torno a 1470 la moda de la figuración marginal llegó al área flamenca, donde la producción libraria había alcanzado un gran desarrollo e independencia desde comienzos del siglo XV. Hacia ese año, la manera francesa de comprender la decoración marginal fue introducida en Brujas por un artista extranjero a quien a veces se ha identificado con Philippe de Mazerolles, activo en esa ciudad desde 1469 y de indudable formación francesa ${ }^{16}$. Bajo el influjo de ese artista, quienquiera que fuese, muchos miniaturistas flamencos, como el prolífico Willem Vrelant, comenzaron a poblar sus márgenes de drôleries (fig. 9). Sin embargo, esta renovada decoración marginal duró muy poco. En los años setenta un artista genial a quien a partir de los estudios de Pächt se denomina convencionalmente maestro de María de Borgoña revolucionó la decoración marginal de los manuscritos flamencos dando origen, junto con un acercamiento a la manera de la pintura de caballete en la forma de tratar las escenas de las miniaturas, a la que Durrieu denominara «Escuela de Gante-Brujas», característica del último período de esplendor de la miniatura flamenca ${ }^{17}$. La decoración marginal propia de esta escuela se caracteriza por presentar sobre un fondo dorado uniforme mariposas, insectos, flores... en aparentemente fortuita dispersión y reproducidos con tal precisión que parecen ser elementos reales caídos por azar sobre la página del manuscrito, sobre la que incluso proyectan su sombra (fig. 10) ${ }^{18}$. De esta manera se volvió a cuestionar la planitud con-

14 Avril, François y Reynaud, Nicole: Les manuscrits à peintures en France, 1440-1520, 2. a ed., Flammarion y Bibliothèque nationale de France, París, 1995, pp. 230-231.

15 Avril, François y Reynaud, Nicole: Les manuscrits à peintures..., p. 130.

16 Delaissé, L. M. J.: La miniature flamande. Le mécénat de Philippe le Bon, catálogo de la exposición, Bruselas, 1959 p. 102; Dogaer, Georges: Flemish Miniature Painting in the $15^{\text {th }}$ and $16^{t^{h}}$ Centuries, B. M. Israël, Amsterdam, 1987, p. 121.

17 Durrieu, conde Paul: La miniature flamande aux temps de la cour de Bourgogne (1415-1530), 2." ed., París y Bruselas, 1927, pp. 38-40.

${ }_{18}$ Sobre los antecedentes de esta visión naturalista de la realidad, véanse Pächt, Otto: «Early Italian Studies and the Early Calendar Landscape», Journal of the Warburg and Courtauld Institutes, volumen XIII, Londres, 1950, pp. 21-22 y Meiss, Millard: French Painting... The Limbourgs..., pp. 182-183. 
sustancial al espacio pictórico y el equilibrio entre texto, miniatura y decoración marginal se rompió de manera definitiva. La evolución de los acontecimientos no permitió ya que, como a comienzos del siglo XV, se impusiera de nuevo una decoración marginal en línea con la tradición. Ningún maestro cualificado la reivindicó y, a diferencia de lo que ocurriera con los desnudos márgenes de los Limbourg, los márgenes de naturalista del maestro de María de Borgoña fueron ampliamente imitados. Paralelamente, se produjeron unos cambios en la cultura europea, apuntados por Camille, que propiciaron la irremediable desaparición a medio plazo de la figuración marginal. Según este autor, la difusión de la imprenta y la veneración por el texto propia de la cultura humanista favorecieron la definitiva erradicación de la decoración marginal ${ }^{19}$.

En los primeros años del siglo XVI perduran en los manuscritos flamencos y en otros muchos por ellos influidos márgenes del tipo de la escuela de Gante-Brujas. Su fidelidad fotográfica a la naturaleza no dejaba espacio para nada que pudiera aproximarse a la vieja drôlerie, pero siempre media una distancia entre la ortodoxia de quien propone un modelo y la laxitud interpretativa de quienes lo asumen sin plantearse a fondo sus implicaciones. Por eso los en principio tan racionales y asépticos márgenes surgidos del influjo de la escuela de Gante-Brujas no dejarán de deparar algún que otro desvaído motivo del viejo repertorio de la figuración marginal (fig. 11). En los manuscritos franceses, mientras tanto, domina desde finales del siglo XV un tipo de decoración marginal que acusa la influencia flamenca, pero en la que es frecuente la compartimentación del margen en espacios en cuyo fondo se alternan distintos colores (fig. 12) ${ }^{20}$ así como la inclusión de escenas desarrolladas en ámbitos propios en las que la noción de cuadro va conquistando también el margen.

Si resulta complejo trazar las líneas generales por las que discurrió la historia de la figuración marginal desde el punto de vista externo y formal, aún mucho más complejo resulta dilucidar el carácter de la misma. Janson, en su estudio sobre el simio en el arte de la Edad Media y del Renacimiento, sintetiza de manera brillante la problemática que encierra esta cuestión al comienzo del capítulo en el que trata sobre la presencia del simio en la figuración marginal del período gótico: «El iconógrafo que se aventura en el campo de la drôlerie gótica se enfrenta a una tarea poco envidiable. Su material, disperso por los márgenes de manuscritos de los siglos XIII al XVI (por no mencionar sus correlatos escultóricos: capiteles, sillerías de coro, etc.), es tan vasto que nunca puede pretender abarcar más que una parte. Además se mueve sobre un terreno resbaladizo. Carece de reglas claramente definidas o de pautas de comunicación visual que le guíen y el estudio de los textos ha de resultarle igualmente infructuoso, pues las drôleries, salvo raras excepciones, carecen de función ilustrativa. ¿Cómo determinar, entonces, el nivel de significado apropiado para un motivo dado? ¿Cómo diferenciar entre lo singular y lo convencional, entre la fantasía espontánea y la intencionalidad controlada? Incluso cuando la fuente de un motivo es conocida, no tiene la seguridad de que su significado no haya sido sumergido en el libre juego de formas tan característico del arte gótico marginal» ${ }^{21}$. Aunque en estas líneas Janson deja entrever su propia postura respecto al carácter de la figuración marginal, su testimonio es de gran utilidad para dejar planteadas las dificultades metodológicas inherentes al estudio del mismo y para perfilar las dos

\footnotetext{
19 Camille, Michael: Image on the Edge..., pp. 157-158.

20 Esta solución se gestó en torno a 1465-1470, siendo una de los primeros manuscritos en los que aparece una obra del maestro de Coëtivy, las Horas Rivoire (París, Bibliothèque nationale de France, ms. n. a. lat. 3114). Véase Avril, François y Reynaud, Nicole: Les manuscrits à peintures..., p. 67.

${ }^{21}$ Janson, Horst W.: Apes and Ape Lore in the Middle Ages and the Renaissance, Londres, 1952, p. 163.
} 


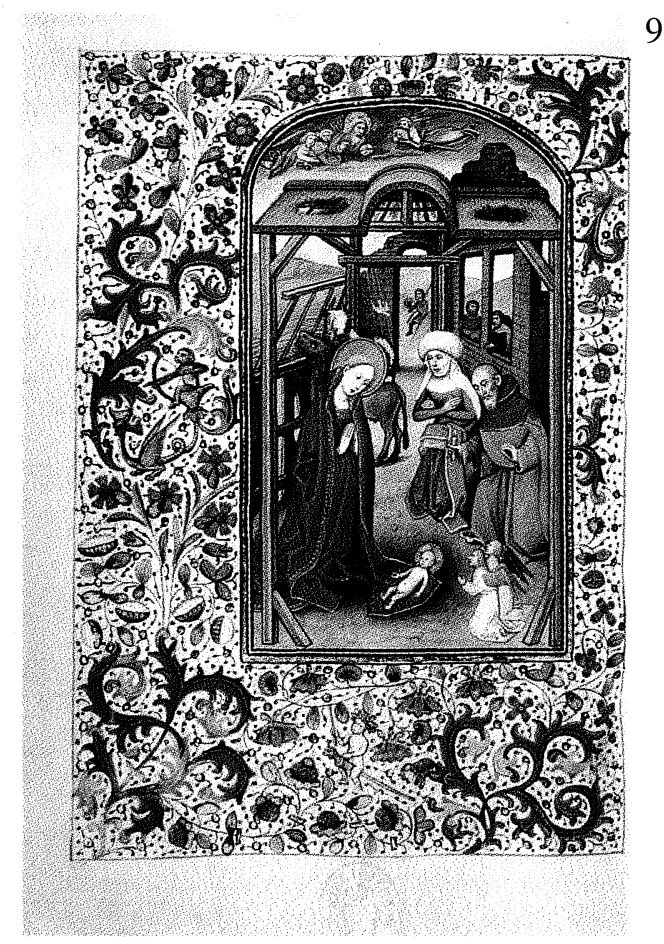

9
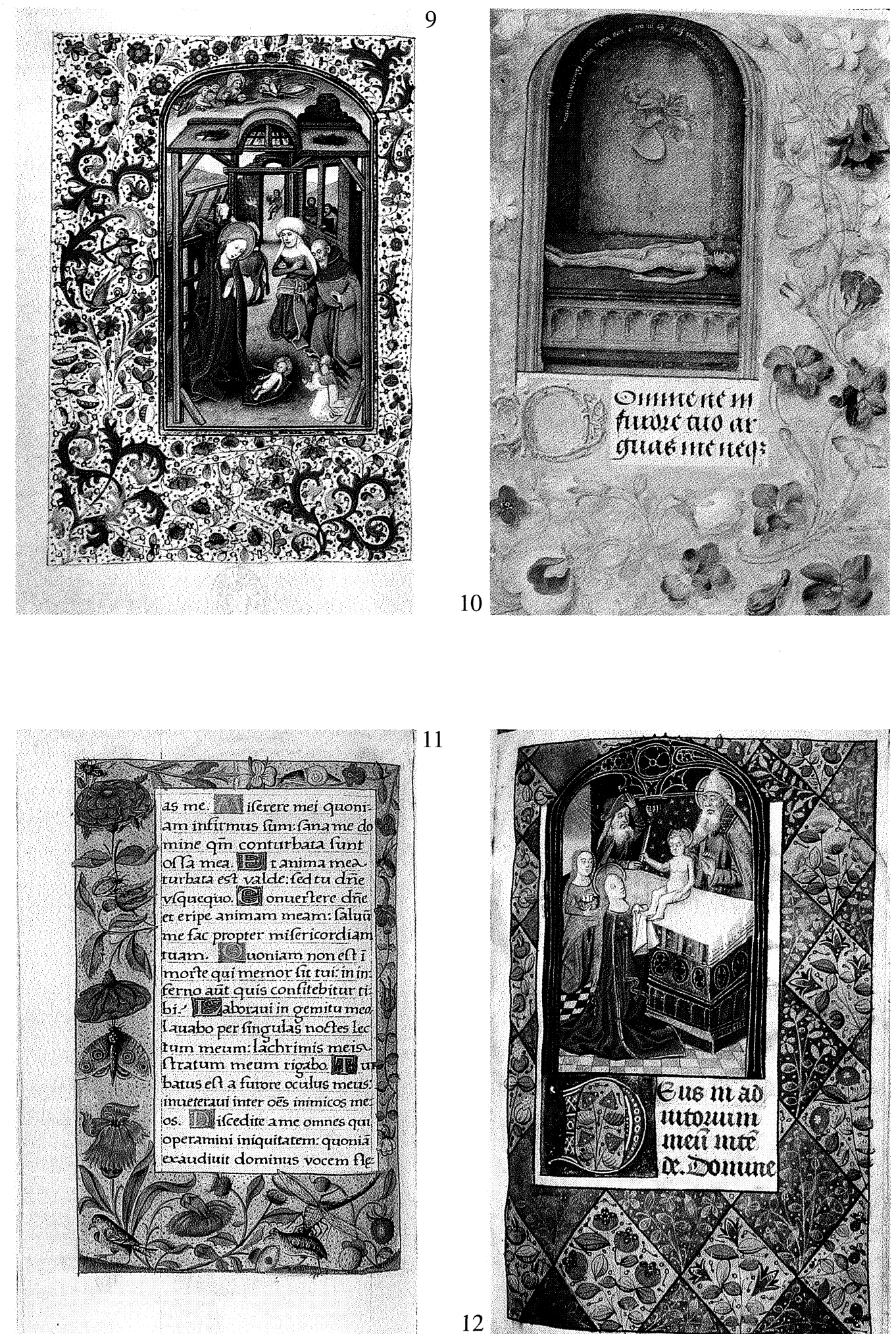

11

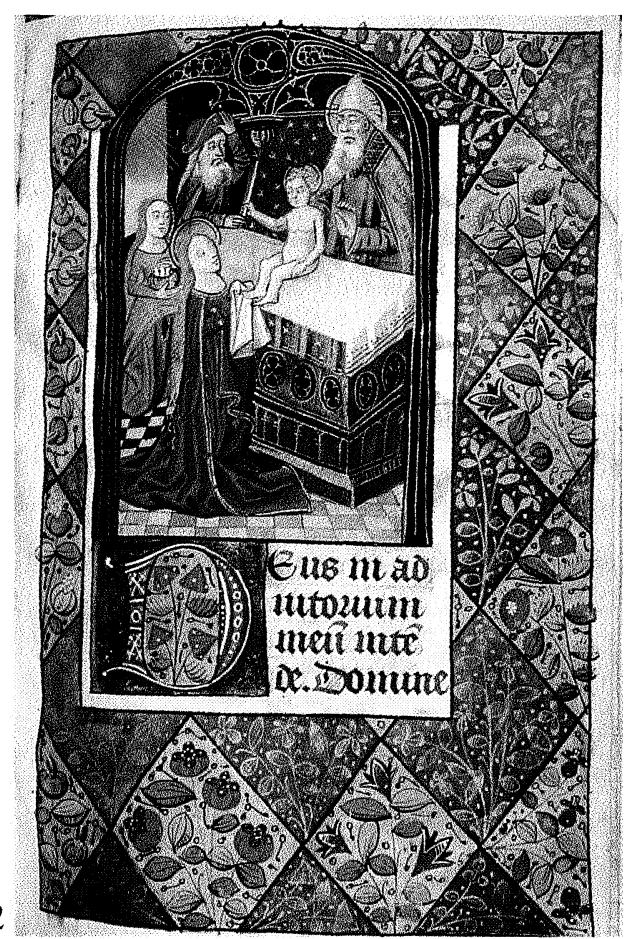

Figura 9. Libro de Horas; Madrid, Biblioteca Nacional, ms. Vit. 24-2, fol. 78v.

Figura 10. Libro de Horas; Madrid, Biblioteca Nacional, ms. Vit. 25-5, fol. 214r.

Figura 11. Libro de Horas; Madrid, Biblioteca Nacional, ms. Res. 187, fol. 77v.

Figura 12. Libro de Horas; Madrid, Biblioteca Nacional, ms. Res. 190, fol. 49r. 
posturas básicas que caben al respecto, a saber, que la figuración marginal cumple una función meramente decorativa u ornamental o que la figuración marginal encierra un significado coherente con el manuscrito - texto y miniatura- que la contiene. La polémica es antigua y sus raíces se encuentran en las posiciones encontradas que a mediados del siglo XIX mantuvieron Champfleury y el conde de Bastard en torno al caracol, uno de los motivos recurrentes en la figuración marginal ${ }^{22}$. El conde de Bastard defendió la presencia del caracol en un manuscrito por él estudiado como un símbolo de la resurrección, ya que aparecía junto a una miniatura en la que se representaba la resurrección de Lázaro y, puesto que el caracol emergía de su concha, la alusión le pareció evidente. Champfleury, sin embargo, justificó la frecuente aparición del caracol en la decoración marginal por ser un bien conocido y omnipresente depredador de los viñedos, negando así cualquier cualidad simbólica a su representación ${ }^{23}$.

Las opiniones en favor de uno o de otro punto de vista han sido numerosas desde entonces. Entre los defensores del carácter esencialmente ornamental de los motivos marginales se encuentra Thompson, que a finales del siglo XIX afirmaba que la decoración de un manuscrito no guarda relación alguna con el contenido del mismo, sino que responde a una tradición cuyos motivos suscitarían la curiosidad o la admiración de su poseedor sin hacerle caer en la cuenta de su disparidad con respecto al texto al que guarnecían ${ }^{24}$. Consecuencia negativa de este planteamiento fue el que durante muchos años apenas se prestara atención a la figuración marginal, dándose incluso el caso de que, como ocurre en el fundamental estudio de Winkler sobre la miniatura flamenca de los siglos XV y XVI, a la hora de reproducir los manuscritos, a menudo se atendía tan sólo a sus miniaturas, prescindiéndose de su decoración marginal ${ }^{25}$. En los años cincuenta, en cambio, distintos autores, aun incidiendo en las mismas ideas, comenzaron a interesarse por el estudio de la figuración marginal. Sobre las drôleries Janson proclama su carencia de finalidad ilustrativa con respecto al texto al que acompañan y su carácter esencialmente visual, idea ésta en la que insiste Klingender ${ }^{26}$, si bien Janson admite que sus temas respondieron originariamente a un contenido que todavía puede rastrearse en distintos grados de disolución en los márgenes de los manuscritos ${ }^{27}$, opinión ésta a la que se aproxima Lyna ${ }^{28}$. Baltrušaitis, por su parte, insiste en la idea del carácter autónomo de la figuración marginal y centra sus esfuerzos en la clasificación de sus distintos motivos y en la búsqueda de sus fuentes ${ }^{29}$.

22 Sobre las opiniones del conde de Bastard y de Champfleury, véanse Randall, Lilian M. C.: «The Snail in Gothic Marginal Warfare», Speculum, volumen XXXVII, Cambridge (Mass.), 1962, p. 360, Davenport, S. K.: «Illustrations...», p. 92 y Camille, Michael: Image on the Edge..., pp. 31-32.

23 Ambas posturas responden, en última instancia, a una actitud ante las imágenes cuya definición se encuentra más allá de cualquier planteamiento historiográfico o metodológico y que se documenta ya en el siglo XVI en las distintas interpretaciones de Pirro Ligorio (en el papel de Champfleury) y de Sebastiano Erizzo (en el papel del conde de Bastard) en torno al reverso de una moneda o medalla neroniana. Véase Haskell, Francis: La historia y sus imágenes. El arte y la interpretación del pasado, Alianza Editorial, Madrid, 1994, p. 84.

${ }^{24}$ Citado en Davenport, S. K.: «Illustrations...», p. 93 y en Camille, Michael: Image on the Edge..., p. 31.

${ }_{25}$ Winkler, Friedrich: Die flämische Buchmalerei des XV. und XVI. Jahrhunderts, E. A. Seemann, Leipzig, 1925. Incluso en la actualidad existen importantes bibliotecas que tan sólo proporcionan reproducciones de aquellas páginas de sus manuscritos que contienen miniaturas, sin valorar las que únicamente presentan decoración marginal.

Klingender, Francis: Animals..., pp. 414-415.

27 Janson, Horst W.: Apes and Ape Lore..., pp. 163-164.

28 Lyna, Frédéric: «La bordure marginale...», p. 4.

29 Baltrušaitis, Jurgis: Réveils..., p. 201. 
Hacia los años sesenta empezaron a surgir voces que hablaban en favor del carácter significativo de la figuración marginal. Randall, en primer lugar, habla en términos muy vagos de la relación entre texto y figuración marginal en las páginas principales de los manuscritos, mientras afirma que la falta de orden parece imperar en las demás ${ }^{30}$. Meiss, aun cuando no llega a formular una teoría general sobre el carácter de la figuración marginal, se inclina claramente a favor de su carácter significativo cuando afirma, para justificar sus motivos marginales, que el maestro de las Iniciales de Bruselas leía cuidadosamente los textos que ilustraba y que se divertía satirizando la vida intelectual del momento con sus monstruos ${ }^{31}$ o cuando ofrece una aquilatada interpretación de los caracoles del margen del folio $168 \mathrm{v}$ de las Très Riches Heures del duque de Berry en relación con la escena de la multiplicación de los panes y de los peces a la que acompañan recordando su carácter voraz, a la vez que su condición de manjar ${ }^{32}$. Las depuradas interpretaciones de Meiss junto con la observación hecha por Schapiro en su reseña a la obra de Randall sobre la necesidad de no limitarse a la alternativa entre el carácter simbólico o decorativo de la figuración marginal y sobre la oportunidad de considerar una aproximación distinta a la misma, esencialmente poética ${ }^{33}$, allanaron el camino al punto de vista de Davenport, que, al estudiar las imágenes de los márgenes de un Roman d'Alexandre concluido en 1344 e iluminado probablemente en Brujas (Oxford, Bodleian Library, ms. Bodley 264), observa que un tercio de las mismas ilustra directamente pasajes del texto del roman y que en la mayor parte de los casos en los que la figuración marginal se aparta de la directa ilustración del texto es posible detectar en ella una referencia oblicua al texto, un desarrollo o amplificación de la narración. Así, en el margen inferior del folio 79v de este manuscrito, por ejemplo, aparece representado el funeral del zorro (que finge su muerte para apresar más fácilmente al gallo) insistiendo de esta manera en la idea de engaño de la escena principal de esa página, en la que Alejandro, disfrazado, evita ser descubierto. A partir del estudio de este manuscrito, que, probablemente, no sea sino una excepción, Davenport se pronuncia a favor de la existencia de una relación íntegra entre texto y figuración marginal y, si bien reconoce la dificultad de aplicar su sistema de interpretación a los casos, mayoritarios, en los que el texto es de carácter sagrado y la figuración marginal es de carácter profano, está convencido de que merece la pena intentarlo ${ }^{34}$. La idea es recogida por Verdier, que se hace eco de los planteamientos de Davenport y presenta ejemplos de referencias oblicuas al texto o a la miniatura en la figuración marginal de varios libros de horas ${ }^{35}$.

Las últimas aportaciones sobre el carácter de la figuración marginal inciden en el carácter significativo de la misma. Camille incluye la figuración marginal dentro de una categoría más amplia del arte medieval: la categoría de lo marginal. Exigida por el concepto de orden

30 Randall, Lilian M. C.: Images in the Margins..., p. 19.

31 Meiss, Millard: French Painting... The Late Fourteenth..., 1. cit.

32 Meiss, Millard: The Master of the Breviary of Jean sans Peur and the Limbourgs, Oxford University Press, Londres, 1971, p. 15.

33 Schapiro, Meyer: Estudios sobre el arte de la Antigüedad tardía, el cristianismo primitivo y la Edad Media, Alianza Editorial, Madrid, 1987, p. 181.

${ }^{34}$ Davenport, S. K.: «Illustrations...», pp. 83-86, 89 y 94.

35 Verdier, Philippe: «Woman in the Marginalia...», pp. 122-123 y 126-127. Este autor, por ejemplo, comenta cómo en el folio 103r de las Horas de Jeanne d'Évreux, dentro de las horas de San Luis, el tema de Filis y Aristóteles que aparece en el bas-de-page puede referirse de manera indirecta a la miniatura de esa misma página, en la que se representa a San Luis y a su confesor, aludiendo humorísticamente la figuración marginal a la voluntaria continencia de San Luis para con su esposa en relación con las versiones más antiguas de la historia de Filis y Aristóteles, en las que la protagonista femenina no es una cortesana, sino la propia mujer de Alejandro, a la que Aristóteles, que acaba burlado, trata de apartar del trato con su esposo para que éste no se distraiga de los asuntos de gobierno. 
inherente a la mentalidad de aquel período, lo marginal, según Camille, se manifiesta en diferentes ámbitos (el monasterio, la catedral, la corte, la ciudad...) en relación con la dinámica de la sociedad y se caracteriza por ser un ámbito de expresión de los conflictos sociales y psicológicos de cada momento, aunque no sirva sino para mantener las estructuras que aparentemente ridiculiza. Desde este punto de vista, para Camille la figuración marginal de los manuscritos es siempre consciente del texto y, antes que decorarlo, lo glosa, parodia o, en suma, problematiza ${ }^{36}$. Müller insiste en esta línea y trata de concretar las raíces sociales y, sobre todo, culturales de este fenómeno en lo que a la miniatura se refiere ${ }^{37}$.

Todas estas ideas enlazan con otra cuestión no menos vidriosa que, para mayor complejidad de la polémica en torno al carácter de la figuración marginal, se solapa sobre la misma: la visión del margen como ámbito para la libertad del artista medieval, libertad entendida unas veces desde el punto de vista compositivo y formal pero con mayor frecuencia argumentada con respecto al contenido, con la pretensión de dotar a los márgenes de un carácter contestatario lejano, sin duda, a su espíritu original y ajeno al afán moralizador que aquí, como en el caso de las sillerías de coro, se podría rastrear dada la complementaridad existente a menudo entre lo religioso y lo profano a finales de la Edad Media ${ }^{38}$. Para la realización de la decoración marginal los iluminadores se atendrían a las instrucciones dadas por el comitente o por el responsable de la ejecución del encargo, bien fuera verbalmente o mediante las anotaciones que en algún caso se han conservado ${ }^{39}, \mathrm{y}$, si bien es cierto que estas indicaciones no bastarían para determinar las características de la decoración marginal hasta sus últimos detalles, como parece desprenderse de la queja de un cisterciense inglés en torno a las licencias dadas a los artistas por quienes debieran supervisar su labor ${ }^{40}$, la recurrencia de los temas habla a favor de la tradición, concretada a través de los libros de modelos, como el elemento decisivo a la hora de determinar las características de la figuración marginal.

Ya en otra ocasión manifesté mi opinión particular respecto al carácter, esencialmente decorativo, de la figuración marginal, acorde, por recordar las palabras de Henry, con la «forma» más que con el «fondo» del manuscrito ${ }^{41}$. Su naturaleza, eminentemente visual, desligada, salvo raras excepciones, del texto al que acompaña, no impide que sus temas tengan un claro contenido tomado del contexto cultural del momento y forjado por generaciones de tradición ${ }^{42}$, lo cual hace de ellos merecedores de un estudio iconográfico que indague sobre su lógica interna más que sobre forzadas relaciones con el texto o con la miniatura.

36 Camille, Michael: Image on the Edge..., passim.

37 Müller, Markus: «Fonctions du profane...», p. 30.

38 Mateo Gómez, Isabel: Temas profanos en la escultura gótica española. Las sillerías de coro, Consejo Superior de Investigaciones Científicas, Madrid, 1979, passim.

39 Davenport, S. K.: «Illustrations...», p. 83.

40 Camille, Michael: Image on the Edge..., p. 95.

${ }^{41}$ Gutiérrez Baños, Fernando: «La figuración marginal en la Baja Edad Media: temas del «mundo al revés» en la miniatura del siglo XV», Archivo Español de Arte, tomo LXX, Madrid, 1997, pp. 145-146.

42 Cabe recordar aquí que, según los estudios de Domínguez Rodríguez, no ya la figuración marginal, sino las propias miniaturas de los libros de horas deben más a la tradición que al texto en sí (Domínguez Rodríguez, Ana: Iconografía de los libros de horas del siglo XV de la Biblioteca Nacional, Editorial de la Universidad Complutense de Madrid, Madrid, 1993, tomo I, pp. 8-12). 